\title{
Avaliação histológica dos testículos de cães pré-púberes submetidos à vitrificação com diferentes associações de crioprotetores
}

\author{
Histological evaluation of testicles from prepubertal dogs submitted to vitrification with different
} cryoprotectant associations

Evaluación histológica de testículos de perros prepúberes sometidos a vitrificación con diferentes asociaciones de crioprotectores

\section{Resumo}

Objetivou-se avaliar histologicamente os testículos de cães pré-púberes vitrificados com diferentes associações de crioprotetores. Para tanto foram utilizados 10 testículos de cães pré-púberes que foram fragmentados em amostras de 1 a $2 \mathrm{~mm}^{3}$ e vitrificados em diferentes associações de crioprotetores: dimetilsulfóxido (DMSO)/etilenoglicol (EG), EG/glicerol(GLI) e DMSO/GLI. Após um período de armazenamento, as amostras foram aquecidas e submetidas à histologia clássica e avaliadas quanto à separação celular da membrana basal (SMB), retração da membrana basal (RMB), distinção entre células de Sertoli e espermatogônias (DSE), visualização nuclear (VN) e condensação nuclear (CN). Em todos os grupos vitrificados houve algum grau de desorganização da arquitetura histológica comparado ao controle. Os túbulos seminíferos apresentaram epitélio germinativo pouco desenvolvido, rico em células germinativas, boa diferenciação entre espermatogônias e celulas de sertoli. Os 3 grupos vitrificados apresentaram maior SMB em relação ao controle $(\mathrm{P}<0,05)$ e não diferiram entre si. Todos os grupos foram semelhantes ao controle quanto à $\mathrm{RMB}$ e VN. Quanto à DSE, a associação DMSO/EG não diferiu do controle, nem da associação EG/GLI, no entanto, essa associação e a associação DMSO/GLI foram significativamente inferiores ao controle, sendo essa última o pior resultado $(\mathrm{P}<0.05)$. Com relação à $\mathrm{CN}$, EGLI não diferiu do controle, nem tampouco do DMSO/EG que, por sua vez foi inferior ao controle $(\mathrm{P}<0,05)$ e similar ao DMSO/GLI. Concluiu-se que as associações DMSO/EG e EG/GLI foram as que melhor preservaram a integridade testicular após o processo de vitrificação testicular de cães prépúberes. 
Palavras-chave: Canis familiaris; Conservação pelo frio; Dimetilsulfóxido; Glicerol; Etilenoglicol; Gônada masculina.

\begin{abstract}
The aim of this study was to histologically evaluate the testes of prepubertal dogs vitrified with different cryoprotectant associations. For this purpose, 10 testicles from prepubertal dogs were used, which were fragmented into samples of 1 to $2 \mathrm{~mm}^{3}$ and vitrified in different cryoprotectant associations: dimethylsulfoxide (DMSO)/ethylene glycol (EG), EG/glycerol(GLY) and DMSO/GLY. After a period of storage, the samples were warmed and subjected to classical histology and evaluated for cell separation of the basement membrane (SBM), basement membrane retraction (BMR), distinction between Sertoli cells and spermatogonia (DSS), nuclear visualization (NV) and nuclear condensation (NC). In all vitrified groups there was some degree of disorganization of the histological architecture compared to the control. The seminiferous tubules showed poorly developed germinal epithelium, rich in germ cells, good differentiation between spermatogonia and sertoli cells. The 3 vitrified groups had higher SBM compared to the control $(\mathrm{P}<0.05)$ and did not differ from each other. All groups were similar to the control regarding BMR and NV. As for DSS, the DMSO/EG association did not differ from the control or from the EG/GLY association, however, this association and the DMSO/GLY association were significantly lower than the control, the latter being the worst result $(\mathrm{P}<0.05)$. Regarding NC, EG/GLY did not differ from the control, nor from the DMSO/EG which, in turn, was inferior to the control $(\mathrm{P}<0.05)$ and similar to the DMSO/GLY. It was concluded that the DMSO/EG and EG/GLY association were the ones that best preserved testicular integrity after the testicular vitrification process in prepubertal dogs.
\end{abstract}

Keywords: Canis familiaris; Cold storage; Dimethylsulfoxide; Glycerol; Ethylene glycol; Male gonad.

\title{
Resumen
}

El objetivo de este estudio fue evaluar histológicamente los testículos de perros prepúberes vitrificados con diferentes asociaciones de crioprotectores. Para ello se utilizaron 10 testículos de perros prepúberes, los cuales fueron fragmentados en muestras de 1 a $2 \mathrm{~mm}^{3}$ y vitrificados en diferentes asociaciones crioprotectoras: dimetilsulfóxido (DMSO)/etilenglicol (EG), EG/glicerol (GLI) y DMSO/GLI. Después de un período de almacenamiento, las muestras se calentaron y se sometieron a histología clásica y se evaluaron para la separación celular de la membrana basal (SMB), la retracción de la membrana basal (RMB), la distinción entre células de Sertoli y espermatogonias (DSE), visualización nuclear $(\mathrm{VN})$ y condensación nuclear $(\mathrm{CN})$. En todos los grupos vitrificados hubo algún grado de desorganización de la arquitectura histológica en comparación con el control. Los túbulos seminíferos mostraron epitelio germinal poco desarrollado, rico en células germinales, buena diferenciación entre espermatogonias y células de sertoli. Los 3 grupos vitrificados tuvieron mayor SMB en comparación con el control $(P<0.05)$ y no se diferenciaron entre sí. Todos los grupos fueron similares al control con respecto a RMB y VN. En cuanto a DSE, la asociación DMSO/EG no difirió del control ni de la asociación GLI/EG, sin embargo, esta asociación y la asociación DMSO/GLI fueron significativamente menores que el control, siendo este último el peor resultado $(\mathrm{P}<0.05)$. En cuanto a CN, EG/GLI no difirió del control, ni del DMSO/EG que, a su vez, fue inferior al control $(\mathrm{P}<0.05)$ y similar al DMSO/GLI. Se concluye que las asociaciones DMSO/EG y EG/GLI fuern las que mejor preservaron la integridad testicular tras el proceso de vitrificación testicular en perros prepúberes.

Palabras clave: Canis familiaris; Almacenamiento en frío; Dimetilsulfóxido; Glicerol; Etilenglicol; Gónada masculina.

\section{Introdução}

A sobrevivência e preservação de espécies ameaçadas de extinção depende da conservação da biodiversidade existente e de mecanismos para propagar e preservar o potencial genético desses animais. Assim, técnicas de preservação de gametas e de gônadas, associadas às tecnologias reprodutivas vem sendo cada vez mais pesquisadas e desenvolvidas (Carvalho, 2016).

A vitrificação tem se mostrado um método mais interessante, diante dos métodos tradicionais de criopreservação como a refrigeração e congelação em curva lenta e rápida (Carvalho, 2016), devido a custos reduzidos, rápida execução e bons resultados. Nesta técnica, são utilizadas rápidas taxas de congelação associadas a altas concentrações de crioprotetores para promover o aumento da viscosidade, visando inibir a união de moléculas de água para formar cristais (Lima, et al., 2018a). Assim, o estado vitrificado consiste em um sistema amorfo, que carece de estrutura organizada, mas possui as propriedades mecânicas e físicas de um sólido (Silva, et al., 2019a). Existem diversos relatos sobre a criopreservação testicular em diferentes espécies como camundongo (Schlatt, et al., 2002), hamster (Jahnukainem, et al., 2007), porco (Abrishami, et al., 2010), gato 
(Mota, et al., 2012), cão (Carvalho, 2016) e macaco (Fayomi, et al., 2019). Entretanto, os estudos envolvendo a vitrificação testicular de cães pré-púberes ainda são escassos (Santos, 2018).

Apesar dos avanços obtidos na vitrificação testicular (Lima \& Silva, 2017), os aspectos relacionados aos efeitos em cães pré-púberes devido às elevadas concentrações de crioprotetores não foram ainda relatadas até o presente momento. Para se obter sucesso na criopreservação de um órgão vascularizado, tal como o testículo, é imprescindível que a maioria das células essenciais devam estar viáveis após descongelação e exercendo sua função normal de forma a garantir a sobrevivência de todo o fragmento (Carvalho, 2016). Assim sendo alguns fatores importantes devem ser levados em consideração no momento de se avaliar o sucesso de uma técnica de criopreservação, tais como: A integridade do revestimento epitelial dos túbulos seminíferos em que pode ser avaliada a separação e a retração da membrana basal, a integridade dos núcleos das espermatogônias em que pode ser avaliada a visualização e a condensação nuclear, além da distinção entre espermatogônia e célula de Sertoli (Lima, et al., 2017, 2018a). A avaliação desses parâmetros confere mais credibilidade e maior acurácia no resultado da avaliação (Lima, et al., 2018b).

Estudos sobre criopreservação e avaliação testicular em animais pré-púberes podem servir como base de estudo modelo para desenvolvimento de protocolos que podem ter aplicação em medicina humana (Jark, et al., 2016). No entanto, ainda há muito a ser aperfeiçoado na preservação do potencial reprodutivo de animais pré-púberes. Dessa forma, esse estudo teve como objetivo avaliar por meio da histologia clássica o efeito da vitrificação de fragmentos testiculares de cães pré-

\section{Metodologia}

\subsection{Aspectos éticos e legais}

O presente trabalho seguiu as autorizações éticas exigidas para realização de pesquisa científica envolvendo animais tendo sido submetido e aprovado pela Comissão de Ética para o Uso de Animais da nossa instituição sob o número $08913931 / 2020$.

\subsection{Amostra do estudo}

Foram incluídos na pesquisa, um total de 5 cães machos na fase pré-púbere, clinicamente saudáveis, com idade de 3 a 5 meses, que não apresentaram histórico de doenças relacionadas ao sistema reprodutor, e não estavam fazendo uso de medicamentos, com pelo menos a segunda dose do reforço da vacina polivalente e vermifugados pelo menos uma vez. A raça não foi critério de inclusão ou exclusão.

\subsection{Design de estudo}

Os cães foram submetidos à orquiectomia eletiva apara a obtenção de 5 pares testiculares que foram destinados à fragmentação, gerando vários fragmentos dos quais foram selecionados aleatoriamente 14 fragmentos de aproximadamente 1 a $2 \mathrm{~mm}^{3}$ de cada testículo (Santos, 2018). Esses fragmentos testiculares foram distribuídos da seguinte forma: 2 fragmentos para o grupo controle (não vitrificado) fixado para histologia clássica, e os 12 fragmentos restantes foram destinados à vitrificação (método de superfície sólida). Para a vitrificação, os 12 fragmentos restantes foram divididos em partes iguais para três grupos e imersos em soluções de vitrificação diferentes composta por 3 grupos distintos de associações de crioprotetores: DMSO/EG, EG/GLI e DMSO/GLI.

\subsection{Obtenção dos fragmentos testiculares}

Os testículos obtidos foram colocados em solução salina a $0,9 \%$ em temperatura ambiente $\left(\sim 22{ }^{\circ} \mathrm{C}\right)$ e processados para retirada da túnica albuginica e os demais tecidos circundantes dos testículos, lavado com três banhos sucessivos de 
solução salina a 0,9\%, então, fragmentados com lâminas de bisturi. Em seguida, os fragmentos foram destinados aos respectivos processamentos (fixador histológico para histologia clássica) ou para serem imersos em associações distintas de soluções crioprotetoras para vitrificação.

\subsection{Adição de crioprotetores}

Para certificação de que os cães eram de fato pré-púberes, os epidídimos foram lavados e a solução obtida, avaliada buscando a confirmação da ausência de espermatozoides epididimários.

Os fragmentos foram imersos inicialmente em uma solução de equilíbrio contendo 1,4 M de cada uma das associações de crioprotetores testadas, $0,25 \mathrm{M}$ de sacarose e meio essencial mínimo (MEM) durante 10 minutos à temperatura ambiente ( $22{ }^{\circ} \mathrm{C}$ ). Em seguida foram submetidos à solução de vitrificação contendo $2,8 \mathrm{M}$ de cada uma das associações de crioprotetores testadas, $0,50 \mathrm{M}$ de sacarose, MEM e 10\% de soro fetal bovino (SFB) durante 5 minutos à temperatura ambiente $\left(\sim 22{ }^{\circ} \mathrm{C}\right)$. Após esse processo, os fragmentos foram submetidos à vitrificação propriamente dita por meio da técnica de superfície sólida (Curaba, et al., 2011; Lima \& Silva, 2018).

\subsection{Vitrificação por superfície sólida}

Os fragmentos testiculares foram alocados em poços de placa de cultivo celular contendo as soluções de equilíbrio e de vitrificação. Após o período de exposição a essas soluções, os fragmentos testiculares foram transferidos para um cubo de metal feito com papel alumínio $(10 \mathrm{~cm} \times 10 \mathrm{~cm} \times 10 \mathrm{~cm})$ parcialmente imerso em nitrogênio líquido para vitrificação e imediatamente transferido para criotubos de $2 \mathrm{~mL}$ que posteriormente foram armazenado em cilindros contendo nitrogênio líquido por pelo menos uma semana (Abrishami, et al., 2010; Baert, et al., 2012; Lima, et al., 2018a).

\subsection{Aquecimento de fragmentos testiculares}

Após o período de armazenamento, os criotubos foram removidos dos cilindros e mantido à temperatura ambiente ( $22{ }^{\circ} \mathrm{C}$ ) por um minuto. Depois imersos em banho-Maria a $37{ }^{\circ} \mathrm{C}$ por mais um minuto. Para remoção de crioprotetores, todos os fragmentos foram retirados dos criotubos, alocados em poços de placa de cultivo celular e submetidos a banhos de imersão por 5 minutos em soluções decrescentes de sacarose (0,50M; 0,25M; 0,00M), adicionadas de MEM e 20\% de SFB para remoção dos crioprotetores (Silva, et al., 2019b).

\subsection{Processamento para estudo histológico}

Fragmentos testiculares do grupo controle e aqueles obtidos após a remoção dos crioprotetores foram fixados em solução de Bouin (24 horas). Então, processados para histologia clássica: desidratação, diafanização, impregnação com parafina, blocagem, microtomia $(5 \mu \mathrm{m})$, desparafinização e corado com hematoxilina-eosina para serem analisadas por microscopia óptica (Baert, et al., 2012). Foram avaliados aleatoriamente 4 túbulos seminíferos de 5 campos diferentes, totalizando a avaliação de 20 túbulos seminíferos de cada grupo experimental. Foram avaliados 5 parâmetros: separação celular da membrana basal, retração da membrana basal, distinção espermatogônias/Sertoli, visualização nuclear e condensação nuclear. Para cada parâmetro, foi atribuído um escore que variou de 1 a 3, conforme ilustrado no Quadro 1 (Lima, et al., 2017). 
Quadro 1. Classificação da integridade dos compartimentos celulares de testículos de cães pré-púberes.

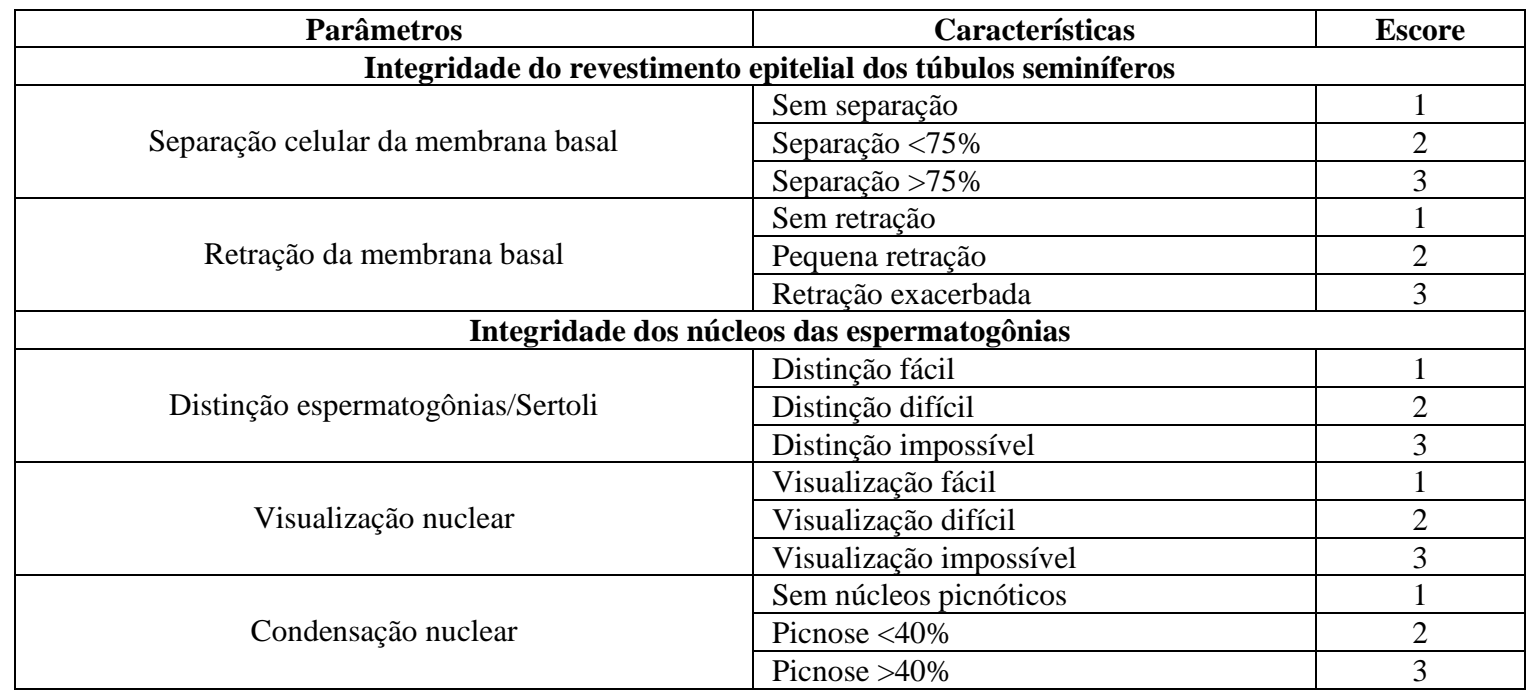

Fonte: Lima, et al. (2017).

\subsection{Análise estatística}

A análise estatística foi realizada usando o RStudio versão 1.3 (Boston, EUA). One-way ANOVA e teste de Tukey foram utilizados para determinar diferenças nas concentrações entre os grupos estudados. Todos os valores foram expressos como média \pm desvio padrão (DP). Diferenças foram consideradas significativas quando $\mathrm{P}<0,05$.

\section{Resultados}

A histomorfologia dos testículos no grupo controle mostrou aspecto normal morfológica e estruturalmente, os túbulos seminíferos com arranjo normal rodeado por tecido conjuntivo com colágeno. A análise histomorfológica do fragmento testicular cães pré-púberes mostrou túbulos seminíferos apresentando epitélio germinativo pouco desenvolvido, rico em células germinativas, incluindo uma boa diferenciação entre espermatogônias e celulas de sertoli. Os cães que foram submetidos à orquiequiotmia que estavam com idade entre 3 e 4 meses, na sua grande maioria apresentaram túbulos com difícil ou nenhuma visualização do lúmen tubular (Figura 1A). Entretanto, os cães que estavam com idade entre 5 e 6 meses, já apresentavam túbulos com alguma visualização do lúmen tubular (Figura 1B). Todas as amostras frescas apresentaram arquitetura bem preservada em relação a todos os parâmetros avaliados (Figura 1C). As amostras dos grupos testes apresentaram variadas alterações dentre dos parâmetros avaliados difererindo do grupo controle em todos os tratamentos (Figura 1D, 1E, 1F). Em todos as amostras analisadas foi comprovada a ausência de espermatozoides, compatível com animais pré-púberes.

Em relação à avaliação dos escores atribuídos, os 3 grupos vitrificados apresentaram maior separação celular da membrana basal em relação ao controle $(\mathrm{P}<0,05)$ e não diferiram entre si. Notadamente, todos os grupos foram semelhantes ao controle quanto à retração da membrana basal e visualização nuclear $(\mathrm{P}>0,05)$. Quanto ao quesito distinção entre espermatogônias e células de Sertoli, a associação DMSO/EG não diferiu do controle, nem da associação GLI/EG, no entanto, essa associação e a associação DMSO/GLI foram significativamente inferiores ao controle, sendo essa última o pior resultado $(\mathrm{P}<0.05)$. Com relação à condensação nuclear, o grupo GLI/EG não diferiu do controle, nem tampouco do grupo DMSO/EG que, por sua vez foi inferior ao controle $(\mathrm{P}<0,05)$ e similar ao grupo DMSO/GLI (Tabela 1). 
Tabela 1. Avaliação histomorfológica de fragmentos testiculares vitrificados com diferentes associações de crioprotetores de cães pré-púberes.

\begin{tabular}{lcccc}
\hline \multicolumn{1}{c}{ Parâmetros (escores 1 a 3) } & Controle & DMSO/EG & EG/GLI & DMSO/GLI \\
\hline Separação da membrana basal & $1,19 \pm 0,39^{\mathrm{a}}$ & $1,77 \pm 0,66^{\mathrm{b}}$ & $1,77 \pm 0,62^{\mathrm{b}}$ & $1,66 \pm 0,64^{\mathrm{b}}$ \\
Retração da membrana basal & $1,21 \pm 0,41^{\mathrm{a}}$ & $1,17 \pm 0,38^{\mathrm{a}}$ & $1,19 \pm 0,39^{\mathrm{a}}$ & $1,20 \pm 0,40^{\mathrm{a}}$ \\
Distinção espermatogônias/Sertoli & $1,00 \pm 0,00^{\mathrm{a}}$ & $1,12 \pm 0,33^{\mathrm{ab}}$ & $1,22 \pm 0,42^{\mathrm{b}}$ & $1,42 \pm 0,50^{\mathrm{c}}$ \\
Visualização nuclear & $1,00 \pm 0,00^{\mathrm{a}}$ & $1,01 \pm 0,01^{\mathrm{a}}$ & $1,00 \pm 0,00^{\mathrm{a}}$ & $1,00 \pm 0,00^{\mathrm{a}}$ \\
Condensação nuclear & $1,00 \pm 0,00^{\mathrm{a}}$ & $1,14 \pm 0,35^{\mathrm{bc}}$ & $1,11 \pm 0,31^{\mathrm{ab}}$ & $1,23 \pm 0,42^{\mathrm{c}}$ \\
\hline
\end{tabular}

Letras sobrescritas diferentes na mesma linha indicam que houve diferença estatística entre os grupos $(\mathrm{P}<0,05)$. Fonte: Autores.

Figura 1. Avaliação histomorfológica de testículos do grupo controle de cães pré-púberes. A) Cães com idade de 3 a 4 meses; B) Cães com idade de 5 a 6 meses. Ponta de setas apontam para lúmen do túbulo seminífero. C) Estruturas histológicas bem visíveis como a região do lúmen do túbulo seminífero, separação da membrana basal (SMB) ausente, distinção entre células de Sertoli e espermatogônias DSE) evidente, condensação nuclear (CN) sem picnose. D) Foto histológica de amostra vitrificada com (DMSO/EG). E) Foto histológica de amostra vitrificada com (DMSO/GLI). F) Foto histológica de amostra vitrificada com (EG/GLI). HE, 200x.

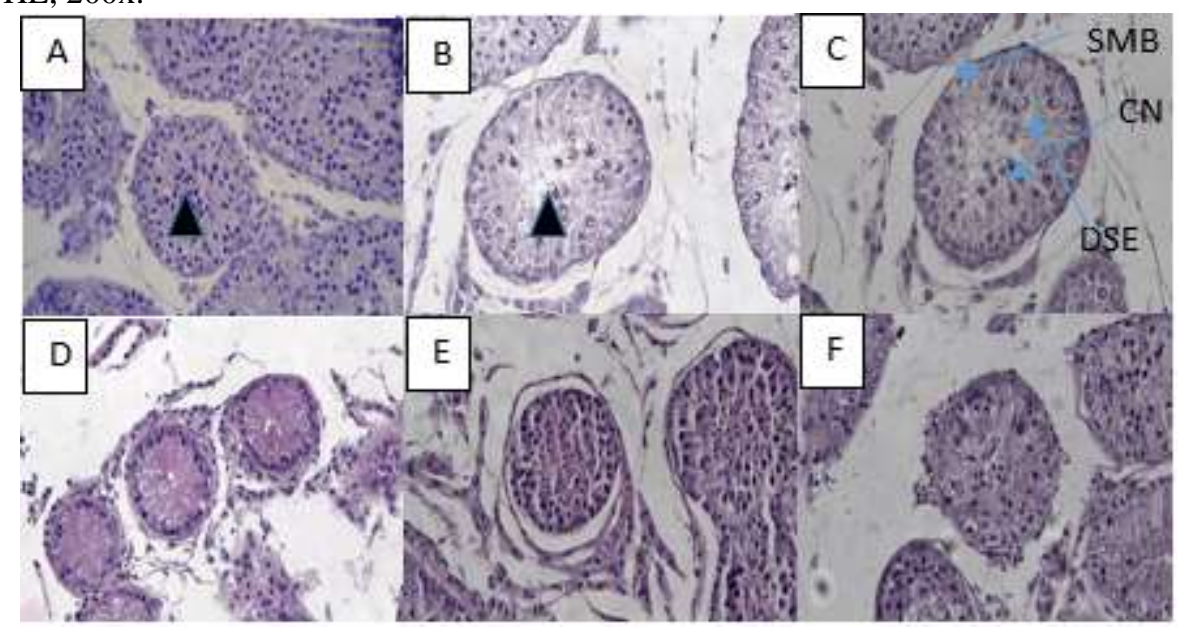

Fonte: Autores.

\section{Discussão}

Um dos desafios na criopreservação testicular é estabelecer a toxicidade dos crioprotetores (Comizzoli, et al. 2012). Os crioprotetores utilizados isoladamente e em elevadas concentrações produzem efeitos deletérios (Unni, et al. 2012). Dessa forma, no presente estudo, avaliamos três diferentes associações de crioprotetores, visando aperfeiçoar um método de vitrificação que mais se aproxime do ideal para conservação da arquitetura testicular após criopreservação em cães prépúberes. Ao nosso conheciemnto, esse foi o primeiro trabalho a realizar a vitrificação testicular de cães pré-púberes.

É de suma importância que as metodologias aplicadas nas avaliações de viabilidade forneçam informações precisas quanto à preservação estrutural e funcional dos criopreservados, tornando-se assim, uma efetiva ferramenta para mensurar a qualidade da amostra preservada, bem como os possíveis danos causados pela criopreservação (Lima, et al., 2018a). Neste trabalho, a avaliação das celulas e estruturas dos túbulos seminíferos por meio da histologia clássica mostrou resultados promissores que podem ser usados como base para a formação de banco de dados e aperfeiçoamento de biotécnicas reprodutivas.

Outros estudos versando sobre vitrificação testicular de anemias pré-púberes já utilizaram associações com DMSO/EG, EG/GLI e DMSO/GLI com concentrações semelhantes às aqui empregadas, todavia esses estudos foram feitos com gatos (Lima, et al., 2017, 2018a). A manuntenção da estrutura morfológica e consequentemente, a funcionalidade das células gonadais após a criopreservação, é alvo das mais diversas pesquisas biotecnológicas, pois é condição sine qua non para 
que se resgate o material genético e se efetive o uso desse material criopreservado nas biotécnicas reprodutivas (Fernandes, et al., 2021).

O DMSO tem baixo peso molecular, conseguindo penetrar rapidamente na célula, liga-se às moléculas de hidrogênio no interior das células e atua impedindo a formação de gelo intracelular (Portillo, et al. 2006). Em estudos envolvendo a utilização dessa substância como crioprotetor na criopreservação testicular, os resultados obtidos têm sido satisfatórios. Gossens, et al. (2008) ao realizarem a criopreservação testicular de camundongos com DMSO, não evidenciaram diferenças significativas quanto à integridade dos túbulos seminíferos comparado ao grupo fresco.

O EG é um álcool também de baixo peso molecular que apresentou as menores taxas de manutenção da integridade dos túbulos seminíferos (Gossens, et al., 2008). No entanto, em nosso trabalho, a associação EG/DMSO permitiu uma boa preservação testicular pós-vitrificação.

Trabalhos anteriores como o de Silva, et al. (2019b) e Santos (2018) também testaram diferentes agentes crioprotetores no processo de vitrificação de testículos, porém o primeiro trabalho utilizou amostra de testiculos de catetos adultos e o segundo usou cães também adultos. Ambos testaram o uso de agentes crioprotetores isoladamente e em associação e chegaram à mesma conclusão, o uso de associação de crioprotetores apresentam melhores resultados. Nosso trabalho testou associações diferentes de agentes crioprotetores e o grupo (EG/CLI) foi quem apresentou melhores resultados de conservaçao da estrutura histologica quando comparado a outros grupos de diferentes associações. Nesses estudos citados anteriormente, a associação testada foi DMSO/EG, que também foi testada em nosso experimento, e apesar de não ter apresentado resultados superiores ao grupo (EG/GLI) manteve um bom grau de conservação comprovando os resultados anteriores e sua eficacia da criopreservação de testiculos mesmo envolvendo espécies diferentes e em diferentes fases de desenvolvimento visto que em cães essa associação obteve bons resultados em animais pré-púberes e púberes.

Quando avaliado nesse trabalho o parâmetro de visualização nuclear, não foi observado diferença estatística entre os grupos tratamentos com diferentes associações de crioprotetores e o grupo controle, resultado semelhante foi observado no estudo de Silva, et al. (2019b) com a vitrificação de testículos de catetos (Pecai tacaju) em que a associação de DMSO/EG ou o uso desses agentes crioprotetores isoladamente não apresentou qualquer diferença estatística quando analisado o parâmetro de visualização nuclear comparado com o grupo controle.

Carvalho (2016) também criopreservou por meio da vitrificação, testículos de cães púberes, porém nao comparou associações de crioprotetores, seu estudo, avaliou dois protocolos de criopreservação (congelamento lento e vitrificação) e dois agentes crioprotetores diferentes (GLI e DMSO) para determinar o melhor método para a criopreservação do testiculo de cães adultos. Seus resultados demostraram que a vitrificação de testículo com DMSO e trealose mostrou melhor sobrevivência celular pós-descongelação do que com GLI, ou mesmo quando comparado ao congelamento lento, com base na avaliação morfológica e dados ultraestruturais. Uma outra constatação de seu trabalho é que o testículo de cães adultos é uma mistura complexa de células germinativas, células de Sertoli, células de Leydig, células mióides peritubulares, vasculatura e tecido conjuntivo intersticial, sendo assim muito mais desafiador obter bons resultados na crioprezervação desse material. Tendo em vista nossos resultados, conjecturamos que o testículo de cães pré-puberes com células ainda indiferenciadas de certa forma cofere um padrão mais homogêneo quando comparado com a heterogeneidade testicular de um animal púbere. O que justificaria os excelentes resultados obtidos nesse trabalho usando além de associações de crioprotetores, também testiculos de animais pré-púberes.

Ali, et al. (2016; 2018) também constataram que o uso dimetilsulfóxido é um melhor agente crioprotetor testicular em ratos adultos e imaturos em comparação com o GLI e o 1,2 propanodiol levando em conta a analise da preservação histologica da estrutura do tubulo seminifero, distinção de celulas de sertoli e espermatogonias, organização e vascularização do tecido intesticial, preservação de celulas de leydig. Esse resultado nos leva a crêr que embora possamos conjecturar que o testiculo 
pré-púbere tenha melhor resistencia aos danos da criopreservação do que o testiculo púbere na espécie canina, essa teoria não pode ser aplicada para todas especies, visto que na especie Rodentia sp. A idade ou fase reprodutiva do individuo obtiveram resultados semelhantes. É importante ressaltar que nesse trabalho os autores não comparam a qualidade da criopreservação entre ratos adultos e pré-púberes, portanto, é necessario mais estudos nesse sentido para se obter mais informações.

A associação DMSO/GLI foi a que menos preservou as características histomorfológicas dos testículos caninos vitrificados, contrariamente ao que oi observado na vitrificação testicular de gatos pré-púberes (Lima, et al., 2017, 2018a). Daí a importância de se considerar no desenvolvimento de protocolos com associações de crioprotetoress que contribuam para manutenção da integridade tecidual e viabilidade celular após o processo de vitrificação é a especificidade de cada espécie quanto às propriedades criobiológicas, interações teciduais e celulares próprias que podem determinar a capacidade de sobrevivência das células e tecidos ao processo de vitrificação (Pukazhenthi, et al. 2011; Comizzoli 2014). Dessa forma, o aprimoramento da utilização de diferentes associações de crioprotetores na preservação testicular de cães poderá contribuir para a conservação de canídeos silvestres.

\section{Conclusão}

Conclui-se que as associações DMSO/EG e EG/GLI foram as que melhor preservaram a integridade testicular após o processo de vitrificação testicular de cães pré-púberes.

\section{Agradecimentos}

Os autores agradecem aos órgãos de fomento Conselho Nacional de Desenvolvimento Científico e Tecnológico (CNPq) pela concessão da bolsa de pesquisadora à L. D. M. Silva e pelo apoio financeiro para o desenvolvimento dessa pesquisa e à Fundação Cearense de Apoio ao Desenvolvimento Científico e tecnológico (FUNCAP) pela concessão da bolsa de mestrado para D. O. Teixeira.

\section{Referências}

Abrishami, M., Anzar, M., Yang, Y. \& Honaramooz, A. (2010) Cryopreservation of immature porcine testis tissue to maintain its developmental potential after xenografting into recipient mice. Theriogenology, 73 (1), 86-96.

Baert, Y., Goossens, E., Saen, D. V., Ning, 1., Veld, P. \& Tournaye, H. (2012). Orthotopic grafting of cryopreserved prepubertal testicular tissue: in search of a simple yet effective cryopreservation protocol. Fertlity and Sterility, 97 (5), 1152-1157.

Carvalho, M.C. (2016). Criopresevação de tecido testicular de cães- Avaliação histológica e ultraestrutural. Dissertação (Programa de Pós-Graduação em Ciência Animal Tropical - Universidade Federal Rural de Pernabunco, Departamento de morfologia e fisiologia animal, Recife.

Comizzoli, P., Songsasen N., Hagedorn, M. \& Wildt, D. E. (2012). Comparative cryobiological traits and requirements for gametes and gonadal tissues collected from wildlife species. Theriogenology, 78 (8), 1666-1681.

Comizzoli P. (2014). Comparative cryobiology of germplasms in non-traditional species. Cryobiology, 69 (3), 506.

Curaba, M., Verleysen, M., Amorim, C. A., Dolmans, M. M., Langendonckt, A. V., Hovatta, O., Wyns, C. \& Donnez J. (2011). Cryopreservation of prepubertal mouse testicular tissue by vitrification. Fertility and Sterility, 95 (4), 1229-1234.

Fayomi, A. P., Peters, K., Sukhwani, M., Valli-Pulaski, H., Shetty, G., Meistrich, M. L., Houser, L., Robertson, N., Roberts, V., Ramsey, C., Hanna, C., Hennebold, J. D., Dobrinski, I. \& Orwig K. E. (2019). Autologous grafting of cryopreserved prepubertal rhesus testis produces sperm and offspring. Science, 363 (6433), 1314-1319.

Fernandes, J. S., Tabosa, B. E. A., Brito, B. F., Silva, H. V. R., Lima, D. B. C. \& Silva, L. D. M. (2021). Influence of different warming temperatures on the vitrified testicular fragments from pre-pubertal cat. Reproduction in Domestic Animals, 56 (10), 1342-1348.

Gossens, E., Frederickx, V., Geens, M., Block, G. \& Tournaye, H. (2008). Cryosurvival and spermatogenesis after allografting prepubertal mouse tissue: comparison of two cryopreservation protocols. Fertility and Sterility, 89 (3), 725-727.

Ali, I. K. A., Kadhim, K. K. \& Al-Salihi, A. R. (2016). Histological and immunohistochemical comparison of Mature rat testis with glycerol, propanediol and dimethylsulphoxide as cryoprotectants. Advances in Animal and Veterinary Sciences, 4 (1), 35-45. 
Ali, I. K. A., Kadhim, K. K. \& Al-Salihi, A. R. (2018). Histological, ultrastructural and immunohistochemical comparison of immature rat testis cryopreserved with glycerol, propanediol and dimethylsulphoxide. Jounal of nEtomology and Zoology Studies, 6 (1), $151-160$.

Jahnukainen, K., Ehmcke, J., Hergenrother, S. D. \& Schlatt, S. (2007). Effect of cold storage and cryopreservation of immature non-human primate testicular tissue on spermatogonial stem cell potential in xenografts. Reprodução Humana, 22 (4), 1060-1067.

Jark, P. C., Raposo, T. M. M., Trindade, A. B., Macente, B. I., Alves, A. E. \& Apparício, M. (2016). Criopreservação de tecidos gonadais para conservação da fertilidade em canídeos e felídeos: realidade ou promessa? Investigação, 15 (9), 14-20.

Lima, D. B. C. \& Silva, L D. M. (2017). Cryopreservation of testicular tissue: an alternative to maintain the reproductive capacity in different animal species. Ciência Rural, 47 (11), 1-8.

Lima, D. B. C. \& Silva, L. D. M. (2018). Vitrificação testicular de felinos pré-púberes. Revista Brasileira de Reprodução Animal, 42 (3-4), $125-128$.

Lima, D. B. C., Silva, T. F. P., Morais, G. B., Aquino-Cortez, A., Evangelista, J. S. A. M., Xavier Junior, F. A. F., Viana, D. A. \& Silva, L. D. M. (2017). Different associations of cryoprotectants for testicular tissue of prepubertal cats submitted to vitrification. Reproduction in Domestic Animals, 52 (supl.2), 235241.

Lima, D. B. C., Silva, T. F. P., Aquino-cortez, A., Leiva-Revilla, J. \& Silva, L. D. M. (2018a). Vitrification of testicular tissue from prepubertal cats in cryotubes using different cryoprotectant associations. Theriogenology, 110, 110-115.

Lima, D. B. C., Silva, L D. M. \& Comizzoli, P. (2018b). Influence of warming and reanimation conditions on seminiferous tubule morphology, mitochondrial activity, and cell composition of vitrified testicular tissues in the domestic cat model. PLoS ONE, 13 (11), 1-18.

Mota, P. C., Ehmcke, J., Westernströer, B., Gassei, K., Ramalho-Santos, J. \& Schlatt, S. (2012). Effects of different storage protocols on cat testis tissue potential for xenografting and recovery of spermatogenesis. Theriogenology, 77 (2), 299-310.

Portillo, L. M. A., Madero, J. I., López, C., León, M. F., Acosta, L., Gómez, C., Delgado, L. G., Gómez, C., Lozano, J. M. \& Reguero, M. T. (2006). Fundamentos de criopreservación. Revista Colombiana de Obstetricia y Ginecologia, 57 (4), 291-300.

Pukazhenthi, B. S., Hagedorn, M., Comizzoli, P., Songsasen, N. \& Wildt, D. E. (2011). Cryopreserving endangered species gametes, embryos and gonadal tissue: challenges, successes and future directions. Cryobiology, 63 (3), 308-309.

Santos J. F. P. (2018) Criopreservação de tecido testicular de cães (Canis lupus familiaris). Dissertação (Mestrado em Ciência Animal e Pastagens) Universidade Federal Rural de Pernambuco, Programa de Pós-Graduação em Ciência Animal e Pastagens, Garanhuns, BR - PE.

Schlatt, S., Samuel Kim, S. \& Gosden, R. (2002). Spermatogenesis and steroidogenesis in mouse, hamster and monkey testicular tissue after cryopreservation and heterotopic grafting to castrated hosts. Reproduction, 124 (3), 339-346.

Silva A. M., Pereira A. F., Silva A. R. (2019a). Testicular tissue cryopreservation and culture as a tool for the conservation of wild mammals. Revista Brasileira de Reprodução Animal, 43 (2), 229-234.

Silva, A. M., Bezerra, L. G. B., Praxedes, E. C. G., Moreira, S. S. J., Souza, C. M. P., Oliveira, M. F., Pereira, A. F., Comizzoli, P. \& Silva, A.R. (2019b). Combination of intracellular cryoprotectants preserves the structure and the cells proliferative capacity potential of adult collared peccary testicular tissue subjected to solid surface vitrification. Cryobiology, 91, 53-60.

Unni, S., Kasiviswanathan, S., D’Souza, S., Khavale, S., Mukherjee, S., Patwardhan, S. \& Bhartiya, D. (2012). Efficient cryopreservation of testicular tissue: effect of age, sample state, and concentration of cryoprotectant. Fertility and Sterility, 97 (1), 200-208. 